\title{
QUEEN'S
UNIVERSITY
BELFAST
}

\section{Interleukins as new prognostic genetic biomarkers in non-small cell lung cancer}

Perez Ramirez, C., Canadas Garre, M. L., Alnatsha, A., Molina, M. A., Robles, A. I., Villar, E., Delgado, J. R., Faus Dader, M. J., \& Calleja Hernandez, M. A. (2017). Interleukins as new prognostic genetic biomarkers in nonsmall cell lung cancer. Surgical Oncology, 26(3), 278-285. https://doi.org/10.1016/j.suronc.2017.05.004

\section{Published in:}

Surgical Oncology

\section{Document Version:}

Peer reviewed version

Queen's University Belfast - Research Portal:

Link to publication record in Queen's University Belfast Research Portal

\section{Publisher rights}

(c) 2017 Elsevier Ltd. All rights reserved. This manuscript version is made available under the CC-BY-NC-ND 4.0 license

$\mathrm{http}: / /$ creativecommons.org/licenses/by-nc-nd/4.0/, which permits distribution and reproduction for noncommercial purposes, provided the author and source are cited.

\section{General rights}

Copyright for the publications made accessible via the Queen's University Belfast Research Portal is retained by the author(s) and / or other copyright owners and it is a condition of accessing these publications that users recognise and abide by the legal requirements associated with these rights.

Take down policy

The Research Portal is Queen's institutional repository that provides access to Queen's research output. Every effort has been made to ensure that content in the Research Portal does not infringe any person's rights, or applicable UK laws. If you discover content in the Research Portal that you believe breaches copyright or violates any law, please contact openaccess@qub.ac.uk. 
INDEX

1 TITLE PAGE

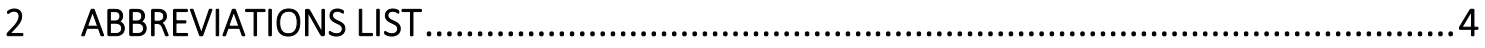

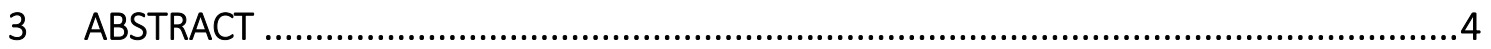

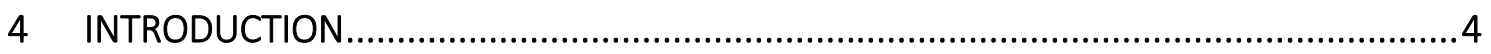

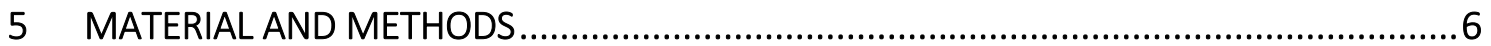

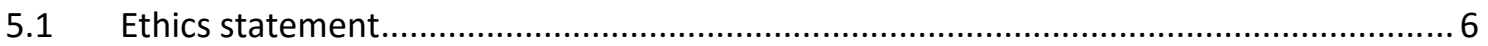

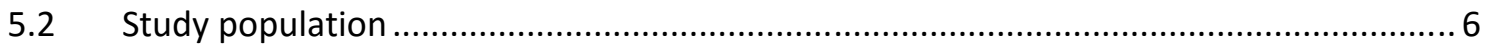

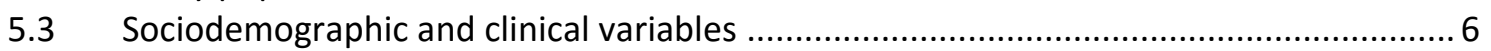

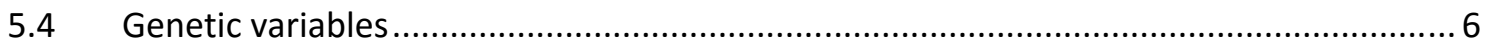

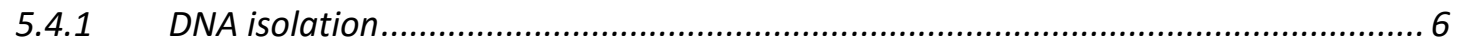

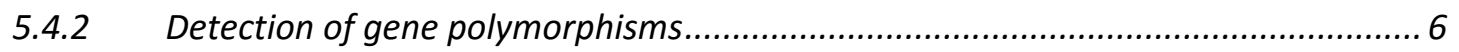

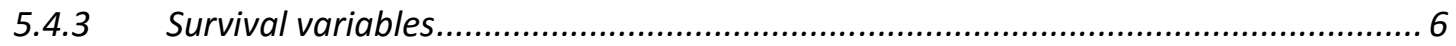

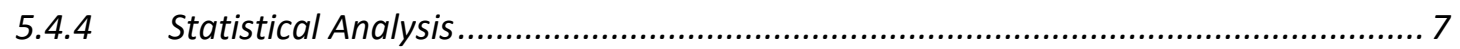

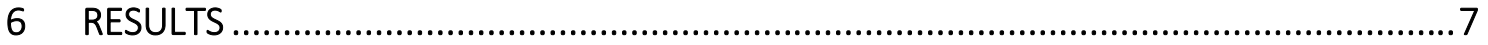

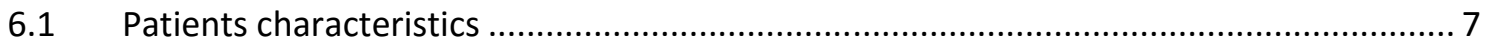

6.2 Influence of clinic-pathologic characteristics on survival ............................................ 7

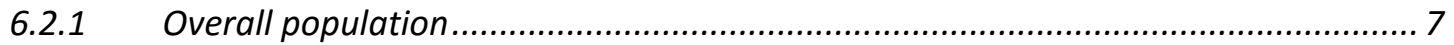

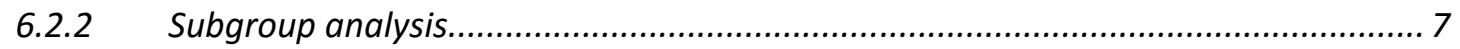

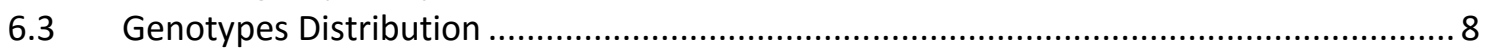

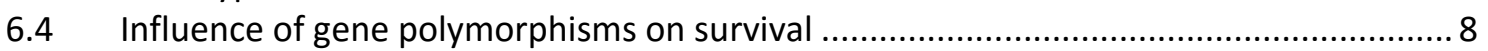

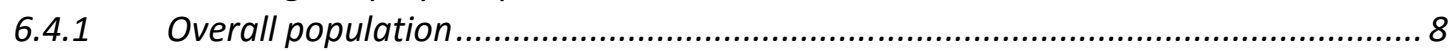

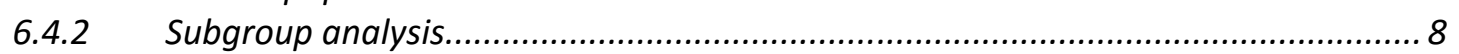

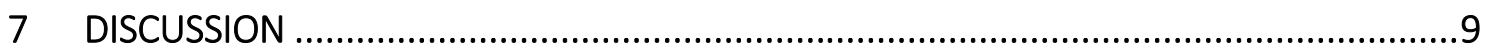

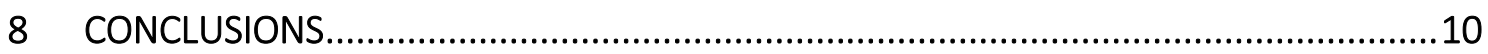

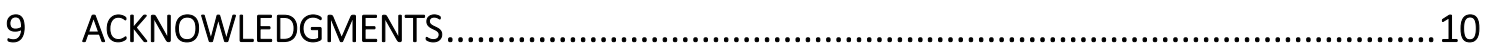

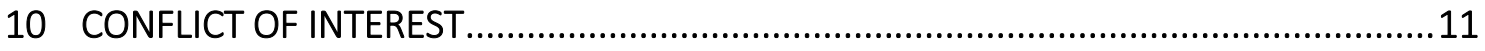

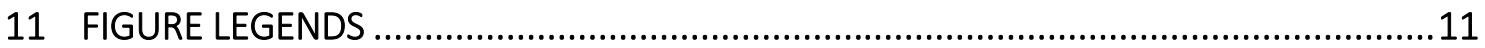

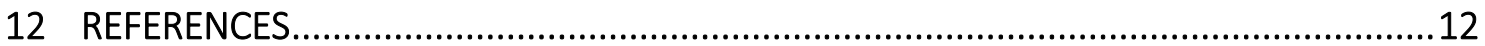




\section{TITLE PAGE}

TITLE:

INTERLEUKINS AS NEW PROGNOSTIC GENETIC BIOMARKERS IN NON-SMALL CELL LUNG CANCER

RUNNING TITLE:

INTERLEUKINS POLYMORPHISMS IN NSCLC

AUTHORS:

Cristina Pérez-Ramírez ${ }^{1,2}$, Marisa Cañadas-Garre ${ }^{3}$, Ahmed Alnatsha ${ }^{1,4}$, Miguel Ángel Molina ${ }^{5}$, Ana I. Robles ${ }^{6}$, Eduardo Villar ${ }^{7}$, Juan Ramón Delgado ${ }^{8}$, María José Faus-Dáder ${ }^{2}$, Miguel Ángel CallejaHernández ${ }^{9}$.

\section{Author for correspondence:}

3 Marisa Cañadas-Garre.

Centre for Public Health

Queen's University of Belfast

c/o Regional Genetics Centre, Level A, Tower Block

Belfast City Hospital, Lisburn Road, Belfast, BT9 7AB

Telephone: 02890638460

Fax: 02890235900

E-mail: marisacgarre@gmail.com

Affiliations:

1 Pharmacogenetics Unit

UGC Provincial de Farmacia de Granada

Instituto de Investigación Biosanitaria de Granada

Complejo Hospitalario Universitario de Granada

Avda. Fuerzas Armadas, 2

Telephone: $\quad+34958020108$

Fax: $\quad+34901021804$

2 Department of Biochemistry

Faculty of Pharmacy

University of Granada

Campus Universitario de Cartuja, $\mathrm{s} / \mathrm{n}$

18071 Granada, Spain

Telephone: +34958243838

4 Department of Molecular Medicine

Faculty of Medicine

University of Tübingen

Geissweg 5

72076 Tübingen

Telephone: $\quad$ +4907071 29-73682

5 Pangaea Biotech, S.L.

Hospital Universitario Quirón Dexeus

C/ Sabino Arana, 5-19. 08028 Barcelona. SPAIN

Tel.: +34 935460135

Fax: +34 935460172

6 National Cancer Institute

37 Convent $\mathrm{Dr}$

$37 / 3060 \mathrm{D}$ 


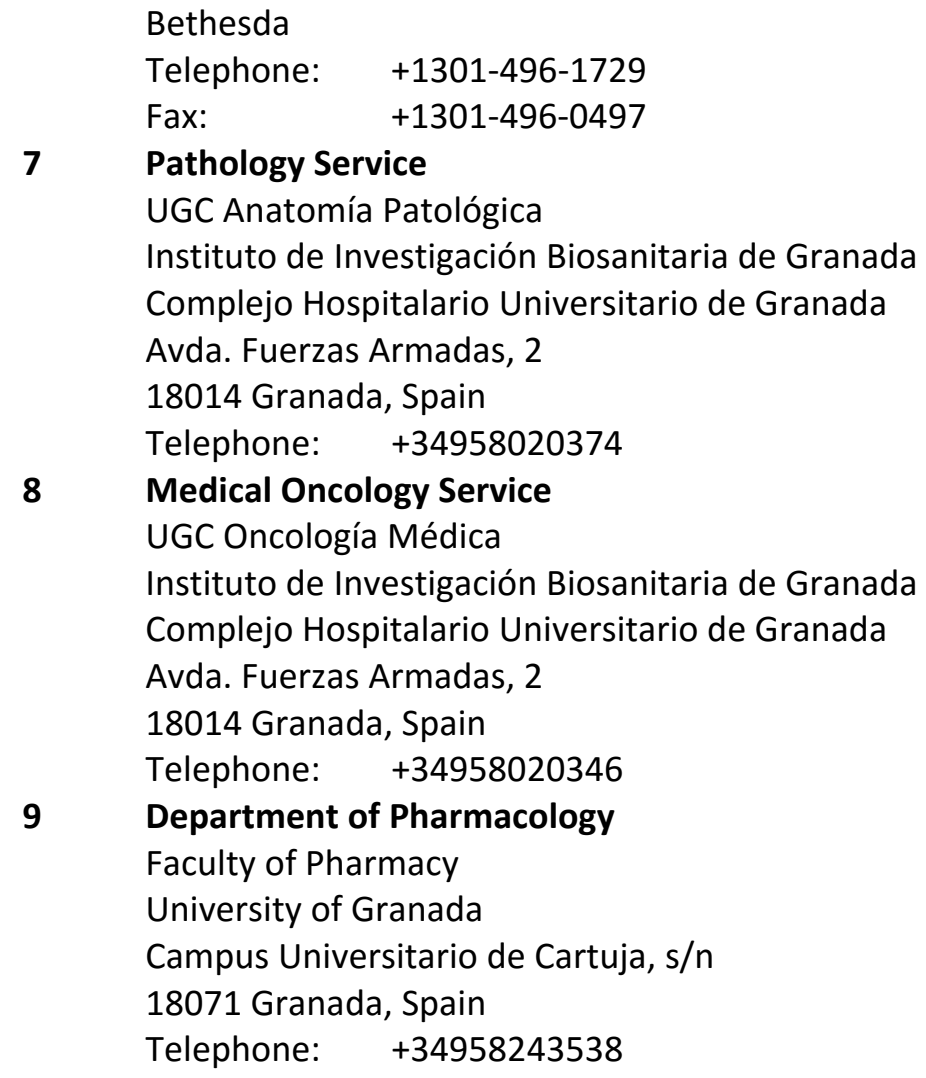

Mails:

Cristina Pérez-Ramírez

Marisa Cañadas-Garre

Ahmed Alnatsha

Miguel Ángel Molina

Ana I. Robles

Eduardo Villar

Juan Ramón Delgado

María José Faus-Dáder

Miguel Ángel Calleja Hernández cperezramirez87@gmail.com marisacgarre@gmail.com r.j.b-man@hotmail.com mamolina@pangaeabiotech.com Ana_Robles@nih.gov eduardovillar6@gmail.com juanramondelgado@gmail.com mfaus@ugr.es mangel.calleja.sspa@juntadeandalucia.es

\section{KEYWORDS:}

PLATINUM BASED CHEMOTHERAPY

NON-SMALL CELL LUNG CANCER

SURVIVAL

POLYMORPHISMS

INTERLEUKINS

\section{WORD COUNT (excluding references and figure legends):}

Abstract: $\quad 168$ words

Main Text: 3083 words

FUNDING:

This work was partly supported by a contract for Marisa Cañadas-Garre (Técnicos de Apoyo Subprogram. CA12/00097) from Instituto de Salud Carlos III, Ministerio de Economía y Competitividad and a research grant for Cristina Pérez-Ramírez (FPU12/04722), from Ministerio de Educación, Cultura y Deporte. 


\section{ABBREVIATIONS LIST}

AJCC: American Joint Committee on Cancer

CHUG: Complejo Hospitalario Universitario de Granada

$\mathrm{Cl}$ : Confidence Interval

EGFR: Epidermal Growth Factor

HR: Hazards Ratio

ILs: Interleukins

NA: Not Available

NSCLC: Non-Small Cell Lung Cancer

OS: Overall Survival

PFS: Progression Free-Survival

SNPs: Single Nucleotide Polymorphisms

\section{ABSTRACT}

\section{BACKGROUND}

Surgery is the standard treatment for early-stage NSCLC, and platinum-based chemotherapy remains as the treatment of choice for advanced-stage NSCLC patients with naive EGFR status. However, overall 5-years relative survival rates are low. Interleukins (ILs) are crucial for processes associated with tumor development. In NSCLC, IL1B, IL6, IL12A, IL13 and IL16 gene polymorphisms may contribute to individual variation in terms of patient survival. The purpose of this study was to evaluate the association between IL gene polymorphisms and survival in NSCLC patients.

\section{METHODS}

A prospective cohorts study was performed, including 170 NSCLC patients (114 Stage IIIB-IV, 56 Stage IIIIIA). IL1B (C>T; rs1143634), IL1B (C>T; rs12621220), IL1B (C>G; rs1143623), IL1B (A>G; rs16944), IL1B (C>T; rs1143627), IL6 (C>G; rs1800795), IL12A (C>T; rs662959), IL13 (A>C; rs1881457) and IL16 (G>T; rs7170924) gene polymorphisms were analyzed by PCR Real-Time.

\section{RESULTS}

Patients with IL16 rs7170924-GG genotype were in higher risk of death ( $p=0.0139$; HR=1.82; $\left.\mathrm{Cl}_{95 \%}=1.13-2.94\right)$ Furthermore, carriers of the TT genotype for IL12A rs662959 presented higher risk of progression in the non-resected NSCLC patient subgroup ( $p=0.0412 ; \mathrm{HR}=4.49 ; \mathrm{Cl}_{95 \%}=1.06$ 18.99). The rest of polymorphisms showed no effect of on outcomes.

\section{CONCLUSIONS}

Our results suggest that IL16 rs7170924-GG and IL12A rs662959-TT genotypes predict higher risk of death and progression, respectively, in NSCLC patients. No influence of IL1B rs12621220, IL1B rs1143623, IL1B rs16944, IL1B rs1143627, IL6 rs1800795, IL13 rs1881457 on NSCLC clinical outcomes was found in our patients.

\section{INTRODUCTION}

Lung cancer is the leading cause of death from cancer worldwide, accounting for $\approx 27 \%$ of all cancer deaths. This type of cancer is the second most diagnosed in the United States (after prostate and breast cancer), with an incidence rate over $14 \%$ in both genders, and 117920 and 106470 estimated new cases for 2016 in men and women, respectively [1]. In accordance with 
the latest cancer statistics, 158080 new cases and 224390 deaths are expected to occur in 2016 [1].

Small cell lung cancer and non-small cell lung cancer (NSCLC) are the two main types of lung cancer. NSCLC represents around $80-85 \%$ of all lung cancer cases and is classified in three subtypes: squamous cell carcinoma, adenocarcinoma and large cell carcinoma. According to the American Joint Committee on Cancer (AJCC), most patients with NSCLC present late-stage (IIIBIV) at the time of diagnosis [2-4].

The standard treatment for early-stage NSCLC is surgery, which may be followed up by platinumbased chemotherapy in patients at high risk of recurrence. Platinum-based chemotherapy remains the treatment of choice for advanced-stage NSCLC. This treatment is given for EGFR (epidermal growth factor receptor) and ALK-rearranged (anaplastic lymphoma kinase) naïve patients and as second line in mutated EGFR patients [5]. Anti-microtubule agents (taxanes and vinca alkaloids), antifolate agents (pemetrexed), or pyrimidine antagonists (gemcitabine) are usually given in combination with cisplatin or carboplatin. In comparison with best supportive care, platinum based chemotherapy has reported more benefits in terms of survival (27.0 vs 10.3 weeks, respectively; $p<0.001)$ and symptom control $[6,7]$. However, the overall response rate (ORR) to platinum-based regimen is about $13-47.2 \%$ and only $16 \%$ of the patients are alive five years after diagnosis [8-24]. Therefore, new therapeutic approaches are urgently needed to improve PFS and OS in advanced stage NSCLC. Pathologic staging is an essential prognostic factor for NSCLC, but a significantly variability in progression and survival among patients with the same stage of disease have been reported, suggesting other factors may influence NSCLC prognosis $[4,25]$. Remarkably, genetic alterations, such as single nucleotide polymorphisms (SNPs), have showed to be related with inter-individual differences in recurrence and survival in NSCLC patients [26-29].

Inflammation is a physiological process induced by immune cell to fight infections and heal wounds. Nevertheless, long-standing inflammation secondary to chronic infection may produce a continuous tissue damage and cellular proliferation that results in metaplasia and dysplasia $[30,31]$. Therefore, there is a notable association between chronic inflammation, infection and early stage of neoplastic development. In fact, clinical and epidemiological studies have reported that $20 \%$ tumors are associated to chronic infection [32]. Interleukins (ILs) are a family of cytokines, which play an essential role on growth, differentiation, and activation of immune cells [33]. Based on above, ILs are crucial for processes associated with tumor development. [34] They act as autocrine and paracrine growth factors, promoting growth and inhibiting apoptosis at the site of inflammation [34]. Remarkably, recent studies have reported a strong effect of IL1B, IL6, IL12A, IL13 and IL16 gene polymorphisms on survival of NSCLC patients [26, 27].

IL1B is a pro-inflammatory cytokine that plays a crucial role on inflammatory response, inducing expression of functional genes involved in inflammation [35]. IL1B may be produced by lung epithelial cells and genetic alteration in this gene has showed an important effect on NSCLC development and progression [36-42]. IL6 is a potent pleiotropic inflammatory cytokine that is secreted by lymphoid and non-lymphoid cells, and is involved in important steps of tumor development, such as proliferation, angiogenesis and apoptosis [43-47]. Interestingly, IL6 is expressed in tumor epithelial cells and polymorphisms in this gene have been associated with poor prognosis in NSCLC patients [26]. IL12A is a multifunctional cytokine generated by dendritic cells, macrophages, neutrophils, and human B-lymphoblastoid cells that regulates immune response and induces anti-angiogenesis activity [48]. Germline variations in IL12A decrease its anti-angiogenic effect, resulting in increasing cancer progression [27]. IL13 is a T-cell derived immunoregulatory cytokine produced by $T$ and $B$ cells, mast cells, basophils, natural killer and dendritic cells that exerts a critical function on allergic reactions, inducing immunoglobulin $E$ secretion from activated human B cells [49]. Particularly in cancer, IL13 has reported to be connected with tumor invasion and metastasis by enhancing MAPK pathway [50]. Thus, 
polymorphisms in this gene may alter regulation of IL13 production, increasing tumor progression [27]. IL16 is a pro-angiogenic cytokine produced by peripheral blood mononuclear cells that modulate T cell growth [51]. Studies in several types of solid tumors and hematologic malignancies have reported a strong association between IL16 levels and cancer progression [51]. Therefore, polymorphisms in IL16 gene that reduce angiogenesis process may be responsible for changes in prognosis of NSCLC patients [27].

Based on above, the identification of genetic variants in ILs may be essential to predict NSCLC clinical outcomes. To date, there are few studies on germline variations in IL genes and lung cancer survival. In this study, we aimed to evaluate the association between IL gene polymorphisms and survival in NSCLC patients. To determine the impact of treatment, we also performed a subgroup analysis according to surgical resection.

\section{MATERIAL AND METHODS}

A prospective cohorts study was conducted.

\subsection{Ethics statement}

This study was performed under the approval of the Complejo Hospitalario Universitario de Granada (CHUG) Ethics and Research Committee and in accordance with the declaration of Helsinki. A written informed consent form was signed by the patients for blood sample collection and genotyping analysis. The identification of samples was based on non-patient codes.

\subsection{Study population}

This study included 170 NSCLC patients recruited in CHUG, Granada, Spain, diagnosed between 2003-2015 and followed up until February 2016. The inclusion criteria for the group of patients were age $\geq 18$ years, histologically or cytologically confirmed diagnosis of NSCLC (stages I-IV), an Eastern Cooperative Oncology Group (ECOG) performance status $\leq 2$, an adequate organ function, measurable disease by chest computed tomography scan, no previous treatment and available clinical data.

Patients were treated according to the National Comprehensive Cancer Network guidelines [5]. EGFR status was measured by $\operatorname{cobas}^{\circledR}$ EGFR Mutation Test [52].

\subsection{Sociodemographic and clinical variables}

Sociodemographic information including gender, family history of cancer, previous non-lung cancer, previous lung disease, smoking status and age at diagnosis was collected from clinical records. Histopathological data (tumor histology and stage), therapeutic procedure and EGFR status were also collected. Tumors were classified in accordance with the guidelines of the AJCC staging system [53].

\subsection{Genetic variables}

\subsubsection{DNA isolation}

Blood samples $(3 \mathrm{ml})$ were collected in BD Vacutainer ${ }^{\circledR}$ K3E Plus Blood Collection Tubes. Genomic DNA was isolated using the QIAamp DNA Mini Kit (QiagenGmBH, Hilden, Germany) according to the manufacturer's instructions for DNA purification from blood and stored at 40 ㄷ.

\subsubsection{Detection of gene polymorphisms}

IL1B (C>T; rs1143634), IL1B (C>T; rs12621220), IL1B (C>G; rs1143623), IL1B (A>G; rs16944), IL1B (C>T; rs1143627), IL6 (C>G; rs1800795), IL12A (C>T; rs662959), IL13 (A>C; rs1881457) and IL16 (G>T; rs7170924) gene polymorphisms were analyzed by Real-Time PCR using TaqMan ${ }^{\circledR}$ probes. Genotyping methodology was previously described [54]. 


\subsubsection{Survival variables}

Survival was measured through OS and PFS. OS was evaluated as time from cancer diagnosis until final follow-up or death and PFS was calculated as the time from initiation of treatment to relapse, death or last known follow-up. Mortality related data were obtained from clinical records and the population-based Cancer Registry of Granada.

\subsubsection{Statistical Analysis}

Quantitative data were expressed as the mean ( \pm standard deviation) for normally-distributed variables or medians and percentiles (25 and 75$)$ for non-normal distributed variables. The Shapiro-Wilks test was used to assess normality.

The Kaplan-Meier method and the log-rank test were used to analyze associations between survival with demographic, clinical and genetic variables. Multivariable Cox proportional hazard regression model (backward stepwise method) was used to obtain the adjusted hazards ratio (HR) and $95 \%$ confidence interval $\left(\mathrm{Cl}_{95 \%}\right)$ for potential prognostic factors for survival.

All tests were two-sided with a significance level of $p<0.05$. Data analysis was performed using R 3.0.1 [55].

Hardy Weinberg equilibrium and pairwise haplotype frequencies were estimated using the free, open-source whole genome association analysis toolset PLINK [56].

\section{RESULTS}

\subsection{Patients characteristics}

A total of 170 NSCLC patients were enrolled in the study. The baseline characteristics are summarized in Table 1. Mean age was $60.46 \pm 10.61$ years, 125 were male $(125 / 170 ; 73.53 \%)$ and 114 were stage IIIB-IV $(114 / 170 ; 67.06 \%)$. Surgery was the first course of treatment for 46 patients $(46 / 170 ; 27.06 \%)$ of which $95.65 \%(44 / 46)$ had stage I-IIIA and $4.35 \%(2 / 46)$ stage IIIBIV. During follow-up, 89 death events were recorded. For all patients, median OS and PFS were 32.2 [26.9-52.2] and 15.5 [11.9-18.7] months, respectively.

\subsection{Influence of clinic-pathologic characteristics on survival}

\subsubsection{Overall population}

Median OS was higher in females ( $p_{\text {log-rank }}=0.0183 ; 52.2$ vs 27.0 months; Table S1; Figure S1), squamous cell carcinoma ( $p_{\text {log-rank }}=0.0106 ; 59.4$ vs 26.9 months; Table S1; Figure S2), I, II and IIIA stage ( $p_{\text {log-rank }}<0.001 ; 85.4$ vs 24.2 months; Table S1; Figure S3) and surgery as first course of treatment ( $p_{\text {log-rank }}<0.001 ; 114.0$ vs 24.5 months; Table S1; Figure S4)

Median PFS was associated with previous lung disease ( $p_{\text {log-rank }}=0.0152 ; 23.2$ vs 13.6 months; Table S2; Figure S5), squamous cell carcinoma ( $p_{\text {log-rank }}=0.0353 ; 20.8$ vs 15.3 months; Table S2; Figure S6), I, II and IIIA stage ( $p_{\text {log-rank }}<0.001 ; 48.3$ vs 10.9 months; Table S2; Figure S7) and surgery as first course of treatment ( $p_{\text {log-rank }}<0.001 ; 83.9$ vs 10.2 months; Table S2; Figure S8)

\subsubsection{Subgroup analysis}

In the subgroup of resected NSCLC patients, OS and PFS were not associated with clinical or demographic characteristics (Tables S3, S4). However, median OS was higher in female ( $p_{\text {log- }}$ $r_{r a n k}=0.012 ; 47.4$ vs 21.4 months; Table S5; Figure S9) and squamous cell carcinoma ( $p_{\text {log- }}$ $r_{\text {rank }}=0.032 ; 41.8$ vs 22.7 months; Table S5; Figure S10) in non-resected NSCLC patients. Median PFS was also associated with gender ( $p_{\text {log-rank }}=0.013 ; 15.8$ vs 9.1 months; Table S6; Figure S11) in non-resected NSCLC patients. 


\subsection{Genotypes Distribution}

All gene polymorphisms distributions were in agreement with those expected according to the Hardy-Weinberg equilibrium model. Linkage disequilibrium values $D^{\prime}$ and $r^{2}$ are shown in Table S7. In particular, IL1B rs1143627/IL1B rs16944 and IL1B rs1143623/IL1B rs12621220 pairs were in strong linkage disequilibrium.

\subsection{Influence of gene polymorphisms on survival}

\subsubsection{Overall population}

\subsubsection{Overall survival}

The bivariate analysis showed OS to be associated to IL16 rs7170924 gene polymorphism (Table S8). In particular, patients with GG genotype were in higher risk of death compared to those carrying the T-allele ( $\mathrm{p}=0.0057 ; \mathrm{HR}=1.92 ; \mathrm{Cl}_{95 \%}=1.21-3.06$; Table S8). Kaplan-Meier curve for OS according to all genotypes and T-allele of IL16 rs7170924 gene polymorphism is showed in Figure $1 \mathrm{~A}\left(p_{\text {log-rank }}=0.019\right)$ and $1 \mathrm{~B}\left(p_{\text {log-rank }}=0.005\right)$, respectively. Median OS was 27.9 months $\left(\mathrm{Cl}_{95 \%}=23.9\right.$ 39.1) for GG genotype. For GT and TT carriers, the median OS was $64.7\left(\mathrm{Cl}_{95 \%}=27.7\right.$-not reached $[\mathrm{NR}])$ and $85.6\left(\mathrm{Cl}_{95 \%}=16.0-\mathrm{NR}\right)$ months, respectively. Multivariate Cox regression adjusted by gender, tumor histology, and first course of treatment showed that IL16 rs7170924 gene polymorphism was the only independent factor associated to OS $\left(p_{\text {likelihood ratio test }}=1.002 \cdot 10^{-12}\right.$ ) (Table 2).

\subsubsection{Progression free-survival}

Patients carrying the GG genotype for IL16 rs7170924 gene polymorphism presented a trend towards higher risk of progression compared to those carrying the $\mathrm{CT} / \mathrm{CC}$ genotypes, but this was not statistically significant ( $\mathrm{p}=0.0739 ; \mathrm{HR}=1.42 ; \mathrm{Cl}_{95 \%}=0.97-2.09$; Table S9). Kaplan-Meier curves for PFS according to T-allele for IL16 rs662959 gene polymorphism are showed in Figure S12 ( $p_{\text {log-rank }}=0.073$ ). Patients with GG genotype showed a median PFS of 13.6 months $\left(\mathrm{Cl}_{95 \%}=10.2-17.6\right)$, whereas for GT and TT genotypes the median PFS was $17.1\left(\mathrm{Cl}_{95 \%}=11.2-82.3\right)$ and $25.6\left(\mathrm{Cl}_{95 \%}=10.1-\mathrm{NR}\right)$ months, respectively.

\subsubsection{Subgroup analysis}

\subsubsection{Overall survival}

In the resected NSCLC patient subgroup, carriers of the GG genotype for IL16 rs7170924 gene polymorphism were in higher risk of death compared to those with T-allele ( $p=0.0439 ; H R=3.50$; $\mathrm{Cl}_{95 \%}=1.04-11.85$; Table S10). Kaplan-Meier curves for PFS according to T-allele for IL16 rs662959 gene polymorphism are showed in Figure $2 \mathrm{~A}\left(\mathrm{p}_{\text {log-rank }}=0.034\right)$. Median OS for TT carriers was $126.0\left(\mathrm{Cl}_{95 \%}=85.6-\mathrm{NR}\right)$ months, whereas for $\mathrm{GG}$ and GT genotype were not reached. Multivariate Cox regression showed that IL16 rs7170924 gene polymorphism was the only independent factor associated to OS in resected NSCLC patients ( $p=0.0439 ; \mathrm{HR}=3.50 ; \mathrm{Cl}_{95 \%}=1.04-11.85$ ) ( $p_{\text {likelihood ratio test }}=0.03428$ ).

In the subgroup non-resected NSCLC patients, IL16 rs7170924 gene polymorphism was also associated with higher risk of death ( $p_{\text {log-rank }}=0.035$; Table S11). Figure 2B shows Kaplan-Meier curves for OS according to IL16 rs662959 gene polymorphism. Median OS for patients carrying TT genotype was 16.0 ( $\left.\mathrm{Cl}_{95 \%}=5.6-\mathrm{NR}\right)$ months, whereas for $\mathrm{GG}$ and $\mathrm{GT}$ genotypes was 23.2 $\left(\mathrm{Cl}_{95 \%}=18.3-30.7\right)$ and $27.7\left(\mathrm{Cl}_{95 \%}=22.7-\mathrm{NR}\right)$ months, respectively.

\subsubsection{Progression free-survival}

In the resected NSCLC subgroup, patients carrying the TT genotype for IL1B rs1143634 gene polymorphism showed a trend towards higher progression, compared to those with $\mathrm{C}$-allele, but this was not statistically significant ( $\mathrm{p}=0.104 ; \mathrm{HR}=5.69 ; \mathrm{Cl}_{95 \%}=0.70-46.28$; Table S12). KaplanMeier curves for PFS according to C-allele for IL1B rs1143634 gene polymorphism are showed 
in Figure S13 ( $p_{\text {log-rank }}=0.064$ ). Patients with TT genotype showed a median PFS of 15.3 months $\left(\mathrm{Cl}_{95 \%}=\mathrm{NR}-\mathrm{NR}\right)$, whereas for CC genotype was $54.3\left(\mathrm{Cl}_{95 \%}=41.9-\mathrm{NR}\right)$, and for CT was not reached.

IL12A rs662959 gene polymorphism showed influence on PFS only in non-resected NSCLC patients (Table S13). In fact, patients carrying the TT genotype presented higher risk of progression compared to those carrying the $\mathrm{CT} / \mathrm{CC}$ genotypes $\left(\mathrm{p}=0.0332 ; \mathrm{HR}=4.77 ; \mathrm{Cl}_{95 \%}=1.13\right.$ 20.07; Table S13). Kaplan-Meier curves for PFS according to all genotypes and C-allele for IL12A rs662959 gene polymorphism are showed in Figure $3 \mathrm{~A}$ ( $\left.p_{\text {log-rank }}=0.031\right)$ and $3 B\left(p_{\text {log-rank }}=0.018\right)$, respectively. Patients with TT genotype showed a median PFS of 4.3 months ( $\mathrm{Cl}_{95 \%}=3.7-\mathrm{NR}$ ), whereas for CC and CT genotypes, the median PFS was $10.2\left(\mathrm{Cl}_{95 \%}=8.4-13.2\right)$ and $15.0\left(\mathrm{Cl}_{95 \%}=6.0\right.$ NR) months, respectively. A multivariate Cox regression model adjusted by gender and tumor histology was used to evaluate the impact of IL12A rs662959 gene polymorphism on PFS (Table 3). IL12A rs662959 gene polymorphism remained significantly associated with PFS (plikelihood ratio test $=0.001736$ ). Furthermore, non-resected NSCLC patients carrying the A-allele for IL1B rs16944 gene polymorphism showed a trend towards higher risk of progression compared to those with GG genotype, but this was not statistically significant $\left(\mathrm{p}=0.0877 ; \mathrm{HR}=1.45 ; \mathrm{Cl}_{95 \%}=0.95-2.22\right.$; Table S13). Kaplan-Meier curves for PFS according to A-allele for IL1B rs16944 gene polymorphism are showed in Figure S14 ( $p_{\text {log-rank }}=0.0806$ ). Median PFS for carriers of IL1B rs16944-AA genotype was $7.5\left(\mathrm{Cl}_{95 \%}=4.7-\mathrm{NR}\right)$, whereas for AG and GG genotype was $10.0\left(\mathrm{Cl}_{95 \%}=6.5-12.9\right)$ and 15.0 $\left(\mathrm{Cl}_{95 \%}=10.0-19.6\right)$ months, respectively. Similarly, the C-allele of IL1B rs1143627 gene polymorphisms, which was in linkage disequilibrium with IL1B rs16944, presented a trend towards higher risk of progression in non-resected NSCLC subgroup, but this was not statistically significant either ( $\mathrm{p}=0.077 ; \mathrm{HR}=1.45 ; \mathrm{Cl}_{95 \%}=0.45-1.06$; Table S13). Kaplan-Meier curves for PFS according to $\mathrm{C}$-allele for IL1B rs1143627 gene polymorphism are showed in Figure S15 ( $\mathrm{p}_{\text {log- }}$ rank $=0.086$; Table S13). Patients with CC genotype showed a median PFS of 8.0 months $\left(\mathrm{Cl}_{95 \%}=4.7-\right.$ $\mathrm{NR})$, whereas for $\mathrm{CT}$ and $\mathrm{TT}$ genotypes the median PFS was $9.1\left(\mathrm{Cl}_{95 \%}=6.5-14.6\right)$ and 15.0 $\left(\mathrm{Cl}_{95 \%}=10.0-19.6\right)$ months, respectively.

\section{DISCUSSION}

Surgery is the standard treatment for early-stage NSCLC and platinum-based chemotherapy remains as the treatment of choice for advanced-stage NSCLC patients with naïve EGFR status. However, overall 5-years relative survival rates are low, with great inter-individual differences, which may be largely explained due to genetic factors. Several polymorphisms in different genes involved in inflammatory response have been proposed as potential causes of this variability [57].

In this study, 170 not previously treated NSCLC patients from a single institution were enrolled to investigate the potential role of $I L 1 B, I L 6, I L 12, I L 13$ and IL16 gene polymorphisms in clinical outcomes. In the overall population, the GG genotype for IL16 rs7170924 showed to be a poor prognosis factor (higher risk of death) (Table 2), in agreement with a previous study, which showed worse PFS in 651 Caucasian patients (stage I-IV) for those carrying the IL16-GG genotype ( $\mathrm{HR}=0.65 ; \mathrm{Cl}_{95 \%}=0.50,0.83$ for GT/TT vs GG) [27]. We also found that in non-resected NSCLC patients, carriers of the TT genotype for IL12A rs662959 presented higher risk of progression compared to those carrying the $\mathrm{CT} / \mathrm{CC}$ genotypes, in agreement with a previous study (HR=1.41; $\mathrm{Cl}_{95 \%}=1.08,1.83$ for $\mathrm{CT} / \mathrm{TT}$ vS CC) [27]. To date, no other studies have explored the association between IL16 or IL12A and NSCLC outcomes. However, other polymorphisms in IL16 ( $\mathrm{rs4778889,}$ rs11556218, rs1131445) and IL12A (rs568408, rs3212227, rs3181224) have reported association with risk of renal cell cancer, glioma, gastric cancer, lung cancer, nasopharyngeal cancer, hepatocellular carcinoma, cervical and vulvar cancer [39, 58-62].

The mechanism by which IL16 and IL12 influence prognosis in NSCLC is still unknown. Several studies have associated altered serum ILs levels with greater susceptibility to cancer development and progression [63-66]. In colorectal cancer, it has been demonstrated that IL6 is 
overexpressed and may regulate CYP1B1 expression via miR27b [67]. CYP1B1 activates many pro-cancer substances, such as heterocyclic amines and polycyclic aromatic hydrocarbons [68]. Thus, it is possible that IL16 and IL12 may regulate cytochrome P450 enzyme expression via microRNA and subsequently promote pro-carcinogen activation and DNA damage. In addition, cytokines promote a neoplastic phenotype through the activation of a variety of signal pathways that are involved in cell survival, invasion, adhesion, proliferation and migration such as JAK/STAT, PTEN/PI3K/AKT and RAS/RAF/MEK/ERK cascade signaling [69, 70]. Therefore, the promotion of these hallmark cancer pathways may contribute to the development of platinumbased chemotherapy resistance. Based on above, IL16 and IL12A levels may play a crucial role on NSCLC prognosis and drug resistance.

On the other hand, genetic factors may influence production and/or activity of cytokines, causing variations which may influence on cancer prognosis [71-73]. The effect of IL16 rs7170924 and IL12A rs662959 polymorphisms on cytokine levels is still unknown. However, a potential alteration of cytokine secretion by IL16 rs7170924 and IL12A rs662959 polymorphisms may underlie the strong effect on survival observed in NSCLC patients. In our study, no serum IL1B, IL6, IL12A, IL13, IL16 levels assessment was determined, therefore we cannot establish if they were altered in patients with IL16 rs7170924-GG and IL12A rs662959-TT genotypes.

A recent study in 651 Caucasian stage I-IV NSCLC patients reported better OS (HR=0.78; $95 \% \mathrm{Cl}=0.63,0.98$ for $\mathrm{CT} / \mathrm{TT}$ vs CC) and PFS (HR=0.73; $\mathrm{Cl}_{95 \%}=0.57,0.93$ for CT/TT vs CC) for IL1B rs1143634 [27]. In our patients, this SNP, along with IL1B rs12621220, rs1143623, rs16944 and rs1143627, were not associated with clinical outcomes. However, a trend towards higher risk of progression was found for IL1B rs1143634-TT genotype in resected NSCLC patients, and IL1B rs16944-A and IL1B rs1143627-C alleles in non-resected NSCLC patients (not statistically significant). To date, these polymorphisms have not been associated to NSCLC outcomes, despite they have been related to lung cancer susceptibility [41]. IL6 rs1800795 was not associated either with survival in our patients, despite a previous study with 434 Caucasian stage I-IV patients reported that the IL6 rs $1800795 \mathrm{G}$-allele was associated with poor OS [74]. Although the C-allele of rs1881457 polymorphism in IL13 predicted higher risk of progression (HR=1.29; $\mathrm{Cl}_{95 \%}=1.00,1.66$ for AC/CC vs AA) in 651 Caucasian stage I-IV NSCLC patients, this effect was not confirmed in our patients [27].

This study presents a cohort of NSCLC patients recruited from the same hospital and treated under the same protocols and guidelines, which ensures a homogeneous sample regarding treatment administered and measure of survival variables. Although the size of the sample was limited, and some associations may have been underpowered to be detected, the effect of IL16 and IL12A was evident.

In summary, these results suggested that IL16 rs7170924 and IL12A rs662959 polymorphisms may substantially act as prognostic factors in NSCLC patients.

\section{CONCLUSIONS}

Our results suggest that IL16 rs7170924-GG and IL12A rs662959-TT genotypes predict higher risk of death and progression, respectively, in NSCLC patients. No influence of IL1B rs12621220, IL1B rs1143623, IL1B rs16944, IL1B rs1143627, IL6 rs1800795, IL13 rs1881457 on NSCLC clinical outcomes was found in our patients.

\section{ACKNOWLEDGMENTS}

The results of this investigation are part of the doctoral thesis presented by Cristina PérezRamírez at the University of Granada. 


\section{CONFLICT OF INTEREST}

The authors declare that there is not conflict of interest that could be perceived as prejudicing the impartiality of the research reported and there is not any competing financial interest in relation to the work described in this article.

\section{FIGURE LEGENDS}

Figure 1. (A) Kaplan-Meier curve for overall survival according to all genotypes of IL16 rs7170924 gene polymorphism in 170 NSCLC patients. (B) Kaplan-Meier curve for overall survival according to T-alelle of IL16 rs7170924 gene polymorphism in 170 NSCLC patients.

Figure 2. (A) Kaplan-Meier curve for overall survival according to T-allele of IL16 rs7170924 gene polymorphism in the resected NSCLC subgroup. (B) Kaplan-Meier curve for overall survival according to all genotypes of IL16 rs7170924 gene polymorphism in the non-resected subgroup.

Figure 3. (A) Kaplan-Meier curve for progression-free survival according to all genotypes of IL12A rs662959 gene polymorphism in the non-resected NSCLC subgroup.(B) Kaplan-Meier curve for progression-free survival according to C-allele of IL12A rs662959 gene polymorphism in the nonresected NSCLC subgroup.

Figure S1. Kaplan-Meier curve for overall survival according to gender in 170 NSCLC patients.

Figure S2. Kaplan-Meier curve for overall survival according to histology in 170 NSCLC patients.

Figure S3. Kaplan-Meier curve for overall survival according to tumor stage in 170 NSCLC patients.

Figure S4. Kaplan-Meier curve for overall survival according to first course of treatment (divided by surgery) in 170 NSCLC patients.

Figure S5. Kaplan-Meier curve for progression-free survival according to previous lung disease in 170 NSCLC patients.

Figure S6. Kaplan-Meier curve for progression-free survival according to histology in 170 NSCLC patients.

Figure S7. Kaplan-Meier curve for progression-free survival according to tumor stage in 170 NSCLC patients.

Figure S8. Kaplan-Meier curve for progression-free survival according to first course of treatment (divided by surgery) in 170 NSCLC patients.

Figure S9. Kaplan-Meier curve for overall survival according to gender in the non-resected NSCLC subgroup.

Figure S10. Kaplan-Meier curve for overall survival according to histology in the non-resected NSCLC subgroup.

Figure S11. Kaplan-Meier curve for progression-free survival according to gender in the nonresected NSCLC subgroup.

Figure S12. Kaplan-Meier curve for progression-free survival according to T-allele of IL16 rs7170924 gene polymorphism in 170 NSCLC patients.

Figure S13. Kaplan-Meier curve for progression-free survival according to C-allele of IL1B rs1143634 gene polymorphism in the resected NSCLC subgroup.

Figure S14. Kaplan-Meier curve for progression-free survival according to A-allele of IL1B rs16944 gene polymorphism in the non-resected NSCLC subgroup.

Figure S15. Kaplan-Meier curve for progression-free survival according to C-allele of IL1B rs1143627 gene polymorphism in 170 NSCLC patients. 


\section{REFERENCES}

[1] Siegel RL, Miller KD, Jemal A. Cancer statistics, 2016. CA: a cancer journal for clinicians. 2016;66:7-30.

[2] Edge S, Byrd, D.R., Compton, C.C., Fritz, A.G., Greene, F.L., Trotti, A. AJCC Cancer Staging Manual. 7th ed2010.

[3] Herbst RS HJ, Lippman SM. Lung cancer. N Engl J Med. 2008;359:1367-80.

[4] Molina JR, Yang P, Cassivi SD, Schild SE, Adjei AA. Non-small cell lung cancer: epidemiology, risk factors, treatment, and survivorship. Mayo Clin Proc. 2008;83:584-94.

[5] Ettinger DS, Wood DE, Akerley W, Bazhenova LA, Borghaei H, Camidge DR, et al. NCCN Guidelines Insights: Non-Small Cell Lung Cancer, Version 4.2016. Journal of the National Comprehensive Cancer Network : JNCCN. 2016;14:255-64.

[6] Klastersky J, Paesmans M. Response to chemotherapy, quality of life benefits and survival in advanced non-small cell lung cancer: review of literature results. Lung Cancer. 2001;34 Suppl 4:S95-101.

[7] Shajeem O, Behera D, Aggarwal AN. Chemotherapy versus best supportive care in the management of lung cancer. The Journal of the Association of Physicians of India. 2003;51:261-4.

[8] Blumenthal GM, Karuri SW, Zhang H, Zhang L, Khozin S, Kazandjian D, et al. Overall response rate, progression-free survival, and overall survival with targeted and standard therapies in advanced non-small-cell lung cancer: US Food and Drug Administration trial-level and patient-level analyses. Journal of clinical oncology : official journal of the American Society of Clinical Oncology. 2015;33:1008-14.

[9] Cardenal F, Lopez-Cabrerizo MP, Anton A, Alberola V, Massuti B, Carrato A, et al. Randomized phase III study of gemcitabine-cisplatin versus etoposide-cisplatin in the treatment of locally advanced or metastatic non-small-cell lung cancer. Journal of clinical oncology : official journal of the American Society of Clinical Oncology. 1999;17:12-8.

[10] Choi MK, Hong JY, Chang W, Kim M, Kim S, Jung HA, et al. Safety and efficacy of gemcitabine or pemetrexed in combination with a platinum in patients with non-small-cell lung cancer and prior interstitial lung disease. Cancer chemotherapy and pharmacology. 2014;73:1217-25.

[11] Crino L, Weder W, van Meerbeeck J, Felip E. Early stage and locally advanced (nonmetastatic) non-small-cell lung cancer: ESMO Clinical Practice Guidelines for diagnosis, treatment and follow-up. Annals of oncology : official journal of the European Society for Medical Oncology / ESMO. 2010;21 Suppl 5:v103-15.

[12] Fenchel K, Sellmann L, Dempke WC. Overall survival in non-small cell lung cancer-what is clinically meaningful? Transl Lung Cancer Res. 2016;5:115-9.

[13] Gervais R, Robinet G, Clement-Duchene C, Denis F, El Kouri C, Martin P, et al. Pemetrexed and carboplatin, an active option in first-line treatment of elderly patients with advanced nonsmall cell lung cancer (NSCLC): a phase II trial. Lung cancer. 2013;80:185-90.

[14] Hasegawa Y, Miura D, Kitamura C, Suzuki T, Kobayashi K, Sato N. A randomized phase II trial of gemcitabine plus carboplatin: biweekly versus standard schedules in patients with advanced non-small cell lung cancer. Chemotherapy. 2013;59:346-53.

[15] Ichiki M, Kawasaki M, Takayama K, Ninomiya K, Kuba M, Iwami F, et al. A multicenter phase II study of carboplatin and paclitaxel with a biweekly schedule in patients with advanced 
non-small-cell lung cancer: Kyushu thoracic oncology group trial. Cancer chemotherapy and pharmacology. 2006;58:368-73.

[16] Karampeazis A, Vamvakas L, Kentepozidis N, Polyzos A, Chandrinos V, Rigas G, et al. Biweekly Carboplatin Plus Gemcitabine as First-Line Treatment of Elderly Patients With Advanced Squamous Non-Small-cell Lung Cancer: A Multicenter Phase I-II Trial by the Hellenic Oncology Research Group. Clinical lung cancer. 2016.

[17] Kim HJ, Kim TG, Lee HJ, Kim JH, Lim BH, Seo JW, et al. A phase II study of combination chemotherapy with docetaxel and carboplatin for elderly patients with advanced non-small cell lung cancer. Lung cancer. 2010;68:248-52.

[18] Maemondo M, Inoue A, Kobayashi K, Sugawara S, Oizumi S, Isobe H, et al. Gefitinib or chemotherapy for non-small-cell lung cancer with mutated EGFR. The New England journal of medicine. 2010;362:2380-8.

[19] Schuette WH, Groschel A, Sebastian M, Andreas S, Muller T, Schneller F, et al. A randomized phase II study of pemetrexed in combination with cisplatin or carboplatin as firstline therapy for patients with locally advanced or metastatic non-small-cell lung cancer. Clinical lung cancer. 2013;14:215-23.

[20] Soejima K, Naoki K, Ishioka K, Nakamura M, Nakatani M, Kawada I, et al. A phase II study of biweekly paclitaxel and carboplatin in elderly patients with advanced non-small cell lung cancer. Cancer chemotherapy and pharmacology. 2015;75:513-9.

[21] Takatani H, Nakamura Y, Nagashima S, Soda H, Kinoshita A, Fukuda M, et al. Phase I and II trials of vinorelbine with carboplatin for patients 75 years of age or older with previously untreated non-small-cell lung cancer. Clinical lung cancer. 2012;13:347-51.

[22] Belani CP, Einzig A, Bonomi P, Dobbs T, Capozzoli MJ, Earhart R, et al. Multicenter phase II trial of docetaxel and carboplatin in patients with stage IIIB and IV non-small-cell lung cancer. Annals of oncology : official journal of the European Society for Medical Oncology / ESMO. 2000;11:673-8.

[23] Ozkaya S, Findik S, Atici AG, Dirica A. Cisplatin-based chemotherapy in elderly patients with advanced stage (IIIB and IV) non-small cell lung cancer patients. Neoplasma. 2011;58:34851.

[24] Ozkaya S, Findik S, Dirican A, Atici AG. Long-term survival rates of patients with stage IIIB and IV non-small cell lung cancer treated with cisplatin plus vinorelbine or gemcitabine. Experimental and therapeutic medicine. 2012;4:1035-8.

[25] Li T, Kung HJ, Mack PC, Gandara DR. Genotyping and genomic profiling of non-small-cell lung cancer: implications for current and future therapies. Journal of clinical oncology : official journal of the American Society of Clinical Oncology. 2013;31:1039-49.

[26] Gomes M, Coelho A, Araujo A, Azevedo A, Teixeira AL, Catarino R, et al. IL-6 polymorphism in non-small cell lung cancer: a prognostic value? Tumour biology : the journal of the International Society for Oncodevelopmental Biology and Medicine. 2015.

[27] Woods NT, Monteiro AN, Thompson ZJ, Amankwah EK, Naas N, Haura EB, et al. Interleukin polymorphisms associated with overall survival, disease-free survival, and recurrence in nonsmall cell lung cancer patients. Molecular carcinogenesis. 2015.

[28] Perez-Ramirez C, Canadas-Garre M, Alnatsha A, Villar E, Delgado JR, Faus-Dader MJ, et al. Pharmacogenetic predictors of toxicity to platinum based chemotherapy in non-small cell lung cancer patients. Pharmacological research. 2016;111:877-84. 
[29] Perez-Ramirez C, Canadas-Garre M, Molina MA, Robles Al, Faus-Dader MJ, CallejaHernandez MA. Contribution of genetic factors to platinum-based chemotherapy sensitivity and prognosis of non-small cell lung cancer. Mutation research. 2017;771:32-58.

[30] Coussens LM, Werb Z. Inflammation and cancer. Nature. 2002;420:860-7.

[31] Lin WW, Karin M. A cytokine-mediated link between innate immunity, inflammation, and cancer. The Journal of clinical investigation. 2007;117:1175-83.

[32] Aggarwal BB, Vijayalekshmi RV, Sung B. Targeting inflammatory pathways for prevention and therapy of cancer: short-term friend, long-term foe. Clinical cancer research : an official journal of the American Association for Cancer Research. 2009;15:425-30.

[33] Dranoff G. Cytokines in cancer pathogenesis and cancer therapy. Nature reviews Cancer. 2004;4:11-22.

[34] Pollard JW. Tumour-educated macrophages promote tumour progression and metastasis. Nat Rev Cancer. 2004;4:71-8.

[35] Bird S, Zou J, Wang T, Munday B, Cunningham C, Secombes CJ. Evolution of interleukin1beta. Cytokine Growth Factor Rev. 2002;13:483-502.

[36] Lind H, Zienolddiny S, Ryberg D, Skaug V, Phillips DH, Haugen A. Interleukin 1 receptor antagonist gene polymorphism and risk of lung cancer: a possible interaction with polymorphisms in the interleukin 1 beta gene. Lung cancer. 2005;50:285-90.

[37] Wu KS, Zhou X, Zheng F, Xu XQ, Lin YH, Yang J. Influence of interleukin-1 beta genetic polymorphism, smoking and alcohol drinking on the risk of non-small cell lung cancer. Clin Chim Acta. 2010;411:1441-6.

[38] Zienolddiny S, Ryberg D, Maggini V, Skaug V, Canzian F, Haugen A. Polymorphisms of the interleukin-1 beta gene are associated with increased risk of non-small cell lung cancer. International journal of cancer Journal international du cancer. 2004;109:353-6.

[39] Lee KM, Shen M, Chapman RS, Yeager M, Welch R, He X, et al. Polymorphisms in immunoregulatory genes, smoky coal exposure and lung cancer risk in Xuan Wei, China. Carcinogenesis. 2007;28:1437-41.

[40] Asada M, Yasuda H, Ebihara S, Tomita N, Suzuki S, Sato M, et al. Interleukin-1beta gene polymorphisms associated with risk of lung cancer in Japanese. Lung cancer. 2006;54:261-3.

[41] Li Y, Zhao W, Zhao Z, Wu J, Chen L, Ma Y, et al. IL1B gene polymorphisms, age and the risk of non-small cell lung cancer in a Chinese population. Lung cancer. 2015;89:232-7.

[42] Wang S, Chen J, Ten Haken RK, Stanton P, Kong FM. Prognostic value of cytokine profile on survival in non-small cell lung cancer patients treated with radiotherapy. ASCO Annual Meeting Proceedings2015. p. 7525.

[43] Crohns M, Saarelainen S, Laine S, Poussa T, Alho H, Kellokumpu-Lehtinen P. Cytokines in bronchoalveolar lavage fluid and serum of lung cancer patients during radiotherapy -

Association of interleukin-8 and VEGF with survival. Cytokine. 2010;50:30-6.

[44] Naka T, Nishimoto N, Kishimoto T. The paradigm of IL-6: from basic science to medicine. Arthritis research. 2002;4 Suppl 3:S233-42.

[45] Zarogoulidis P, Yarmus L, Darwiche K, Walter R, Huang H, Li Z, et al. Interleukin-6 cytokine: a multifunctional glycoprotein for cancer. Immunome Res. 2013;9:16535.

[46] Liu RY, Song X, Chen P, Lei Z, Miao J, Yi N, et al. Association between IL6 -174G/C and cancer: A meta-analysis of 105,482 individuals. Exp Ther Med. 2012;3:655-64. 
[47] Ishihara K, Hirano T. IL-6 in autoimmune disease and chronic inflammatory proliferative disease. Cytokine Growth Factor Rev. 2002;13:357-68.

[48] Del Vecchio M, Bajetta E, Canova S, Lotze MT, Wesa A, Parmiani G, et al. Interleukin-12: biological properties and clinical application. Clin Cancer Res. 2007;13:4677-85.

[49] Wynn TA. IL-13 effector functions. Annu Rev Immunol. 2003;21:425-56.

[50] Fujisawa T, Joshi BH, Puri RK. IL-13 regulates cancer invasion and metastasis through IL13Ralpha2 via ERK/AP-1 pathway in mouse model of human ovarian cancer. Int J Cancer. 2012;131:344-56.

[51] Richmond J, Tuzova M, Cruikshank W, Center D. Regulation of cellular processes by interleukin-16 in homeostasis and cancer. J Cell Physiol. 2014;229:139-47.

[52] Benlloch S, Botero ML, Beltran-Alamillo J, Mayo C, Gimenez-Capitan A, de Aguirre I, et al. Clinical validation of a PCR assay for the detection of EGFR mutations in non-small-cell lung cancer: retrospective testing of specimens from the EURTAC trial. PloS one. 2014;9:e89518.

[53] Edge SB BR, Compton CC, Fritz AG, Green FL, Trotti A, editors. AJCC Cancer Staging Manual. 7 ed. Springer-Verlag New York. 2010:pp. XV-648.

[54] Jimenez-Varo E, Canadas-Garre M, Henriques Cl, Pinheiro AM, Gutierrez-Pimentel MJ, Calleja-Hernandez MA. Pharmacogenetics role in the safety of acenocoumarol therapy. Thrombosis and haemostasis. 2014;112:522-36.

[55] Team RC. R: A language and environment for statistical computing. [Internet]. 2013 Oct. Available from: http://www.r-project.org/.

[56] Purcell S, Neale B, Todd-Brown K, Thomas L, Ferreira MAR, Bender D, et al. PLINK: a toolset for whole-genome association and population-based linkage analysis. American journal of human genetics. 2007;81.

[57] Perez-Ramirez C, Canadas-Garre M, Molina MA, Robles A, Faus-Dader MJ, CallejaHernandez MA. Main polymorphisms in pathways involved in platinum based chemotherapy in non-small cell lung cancer. Pharmacol Res 2016;Submitted.

[58] Kashfi SM, Behboudi Farahbakhsh F, Nazemalhosseini Mojarad E, Mashayekhi K, Azimzadeh $\mathrm{P}$, Romani $\mathrm{S}$, et al. Interleukin-16 polymorphisms as new promising biomarkers for risk of gastric cancer. Tumour biology : the journal of the International Society for Oncodevelopmental Biology and Medicine. 2016;37:2119-26.

[59] Luo QS, Wang JL, Deng YY, Huang HD, Fu HD, Li CY, et al. Interleukin-16 polymorphism is associated with an increased risk of glioma. Genetic testing and molecular biomarkers.

2014;18:711-4.

[60] Wang Z, Xu Y, Zhu S. Interleukin-16 rs4778889 polymorphism contributes to the development of renal cell cancer in a Chinese population. International journal of clinical and experimental pathology. 2015;8:15228-33.

[61] Hussain SK, Madeleine MM, Johnson LG, Du Q, Galloway DA, Daling JR, et al. Nucleotide variation in IL-10 and IL-12 and their receptors and cervical and vulvar cancer risk: a hybrid case-parent triad and case-control study. International journal of cancer Journal international du cancer. 2013;133:201-13.

[62] Yang Z, Liang Y, Qin B, Zhong R. Meta-analysis of the association between the IL-12B +1188 A/C polymorphism and cancer risk. Onkologie. 2013;36:470-5.

[63] Murakami S, Okubo K, Tsuji Y, Sakata H, Hamada S, Hirayama R. Serum interleukin-12 levels in patients with gastric cancer. Surgery today. 2004;34:1014-9. 
[64] Yellapa A, Bahr JM, Bitterman P, Abramowicz JS, Edassery SL, Penumatsa K, et al. Association of interleukin 16 with the development of ovarian tumor and tumor-associated neoangiogenesis in laying hen model of spontaneous ovarian cancer. International journal of gynecological cancer : official journal of the International Gynecological Cancer Society. 2012;22:199-207.

[65] Yellapa A, Bitterman P, Sharma S, Guirguis AS, Bahr JM, Basu S, et al. Interleukin 16 expression changes in association with ovarian malignant transformation. American journal of obstetrics and gynecology. 2014;210:272.e1-10.

[66] Youssef SS, Mohammad MM, Ezz-El-Arab LR. Clinical Significance of Serum IL-12 Level in Patients with Early Breast Carcinoma and Its Correlation with Other Tumor Markers. Open access Macedonian journal of medical sciences. 2015;3:640-4.

[67] Patel SA, Bhambra U, Charalambous MP, David RM, Edwards RJ, Lightfoot T, et al. Interleukin-6 mediated upregulation of CYP1B1 and CYP2E1 in colorectal cancer involves DNA methylation, miR27b and STAT3. British journal of cancer. 2014;111:2287-96.

[68] Gooderham NJ, Creton S, Lauber SN, Zhu H. Mechanisms of action of the carcinogenic heterocyclic amine PhIP. Toxicology letters. 2007;168:269-77.

[69] Jones VS, Huang RY, Chen LP, Chen ZS, Fu L, Huang RP. Cytokines in cancer drug resistance: Cues to new therapeutic strategies. Biochimica et biophysica acta. 2016;1865:25565.

[70] Baird AM, Gray SG, Richard DJ, O'Byrne KJ. Promotion of a cancer-like phenotype, through chronic exposure to inflammatory cytokines and hypoxia in a bronchial epithelial cell line model. Scientific reports. 2016;6:18907.

[71] Gao LB, Rao L, Wang YY, Liang WB, Li C, Xue H, et al. The association of interleukin-16 polymorphisms with IL-16 serum levels and risk of colorectal and gastric cancer. Carcinogenesis. 2009;30:295-9.

[72] Miteva L, Stanilov N, Deliysky T, Mintchev N, Stanilova S. Association of polymorphisms in regulatory regions of interleukin-12p40 gene and cytokine serum level with colorectal cancer. Cancer investigation. 2009;27:924-31.

[73] Qin X, Peng Q, Lao X, Chen Z, Lu Y, Lao X, et al. The association of interleukin-16 gene polymorphisms with IL-16 serum levels and risk of nasopharyngeal carcinoma in a Chinese population. Tumour biology : the journal of the International Society for Oncodevelopmental Biology and Medicine. 2014;35:1917-24.

[74] Bhat IA, Qasim I, Masoodi KZ, Paul SA, Bhat BA, Rasool R, et al. Significant impact of IL-6 $174 \mathrm{G} / \mathrm{C}$ but inverse relation with $-634 \mathrm{C} / \mathrm{G}$ polymorphism in patients with non-small cell lung cancer in Kashmiri population. Immunological investigations. 2015;44:349-60. 